\title{
Melanoma of unknown primary in the pancreas: should it be considered primary?
}

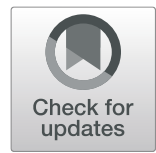

Yanwen Jin, Congdun Ran, Fuyu Li and Nansheng Cheng*

\begin{abstract}
Background: Malignant melanoma is characterized as highly malignant due to its rapid growth and early metastasis. Metastatic melanoma from occult primary is rare. Melanoma of unknown primary in pancreas are even rear. But it is a biologically ill-defined and clinically understudied concept.

Case presentation: In this report, a 43-year-old man was diagnosed with pancreatic carcinoma. Extended total pancreatectomy together with portal vein reconstruction and extensive lymphadenectomy were performed in our hospital. The patient was diagnosed with pancreatic malignant melanoma after pathological examination. He was still alive 20 months after the operation without any evidence of recurrence.

Conclusion: The described case highlights the possibility of primary pancreatic malignant melanoma and the treatment strategies of this rare carcinoma.
\end{abstract}

Keywords: Melanoma of unknown primary, tumor's origin site, Pancreatic carcinoma

\section{Background}

Melanomas can be a challenging malignancy to diagnose and treat. They arise from the melanocytes in the cutaneous, ocular, mucosal, and unknown primaries at an incidence rate of $91.2,5.2,1.3$, and $2.2 \%$, respectively [1]. Melanoma of unknown primary (MUP) is characterized by the finding of metastatic melanoma within the lymph nodes, subcutaneous tissues, and other distant sites without an evident primary lesion. Recently, Song et al. reviewed the diagnosis, epidemiology, staging, etiology, treatment, outcome, and prognosis of MUP [2]. MUP is a biologically ill-defined and clinically understudied concept. Herein, we report a case of pancreatic MUP.

\section{Case presentation}

A 43-year-old man presented to our hospital with a 10day history of mild epigastric pain, without weight loss or jaundice. This patient had a medical history of acute pancreatitis about 6 months before the current

\footnotetext{
* Correspondence: chengnansheng2014@126.com

Department of Biliary Surgery, West China Hospital, Sichuan University, No. 37 Guo Xue Xiang, Chengdu, Sichuan 610041, P.R. China
}

admission. He had a cystic neoplasm in the pancreatic tail 4 months later and was diagnosed with pancreatic pseudocysts at a local hospital. He was a non-smoker and denied any history of prior surgery. After admission, a mass was palpated on the left upper abdomen during physical examination. Routine laboratory tests results for liver function and pancreatic amylase were normal. The tumor markers of carcinoembryonic antigen, carbohydrate antigen 19-9, and carbohydrate antigen 125 were also within normal limits. Abdominal contrast-enhanced ultrasonography revealed multifocal hypoechoic mass in the pancreas (Fig. 1a and b). Magnetic resonance imaging (MRI) of the upper abdomen revealed multifocal masses occupying the entire enlarged pancreas. The lesions were hypointense on T1-weighted image (Fig. 1c) and isointense on T2-weighted image (Fig. 1d). The lesions were heterogeneously enhanced during the arterial phase and portal venous phase (Fig. 1e, f). Contrastenhanced computed tomography $(\mathrm{CT})$ also showed that these lesions were multifocal with low density and the largest one had a diameter of $2.6 \mathrm{~cm}$ (Fig. 1g). Threedimensional vascular reconstruction of CT showed that 


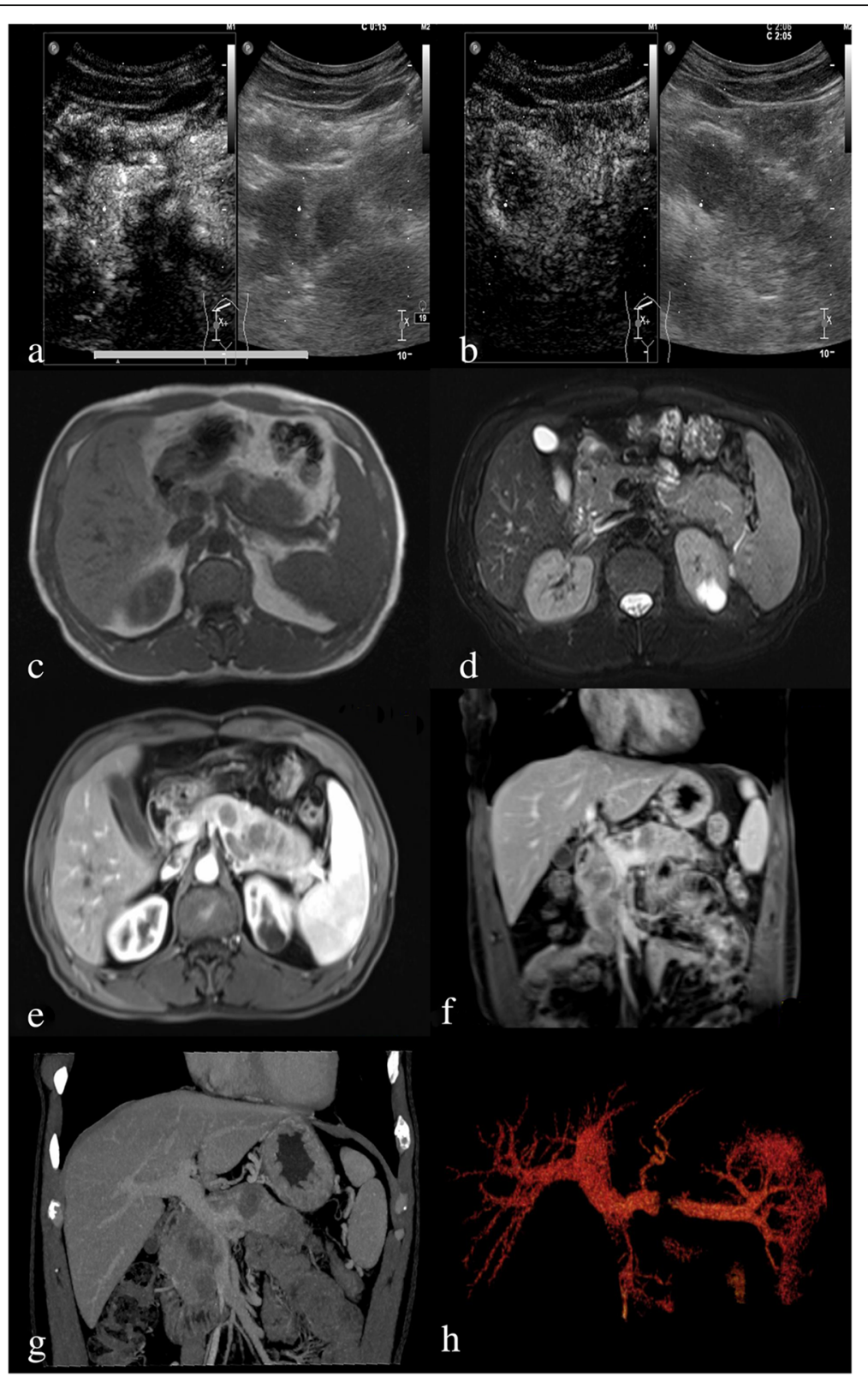

Fig. 1 Contrast-enhanced ultrasonography $(\mathbf{a}, \mathbf{b}), \mathrm{MRI}(\mathbf{c}, \mathbf{d}, \mathbf{e}, \mathbf{f})$ and $C T(\mathbf{g})$ manifestation of pancreatic melanoma. Three-dimensional vascular reconstruction of portal vein system (h)

a tumor thrombus formed in the superior mesenteric vein and central segment of the splenic vein (Fig. 1h).

The patient was diagnosed with pancreatic carcinoma with superior mesenteric and splenic vein tumor thrombus formation. Extended total pancreatectomy together with portal vein reconstruction and extensive lymphadenectomy was performed after thorough exploration of the whole abdominal cavity (Fig. 2a, b). Pathologic examination showed surgical margins were negative. No metastasis was found within the detected lymph nodes. Immunostaining of the pancreatic tumor cells established the diagnosis of pancreatic malignant melanoma: the tumor cells were positive for Human Melanoma Black 45 (original magnification: 400×, Fig. 2c) and S-100 (original magnification: $400 \times$, Fig. 2d) and negative for CA19-9, CA125, CK7, and CK8/18. Detailed medical history-taking and thorough physical examination including ophthalmologic, anal, genital, and nasal cavity were performed, and no other malignant location was found. Full-body positron emission tomography scan 4 months after the operation showed no evidence of malignancy. Therefore, according to diagnostic criteria set forth by Das Gupta [3], the patient was diagnosed with pancreatic MUP. The postoperative 


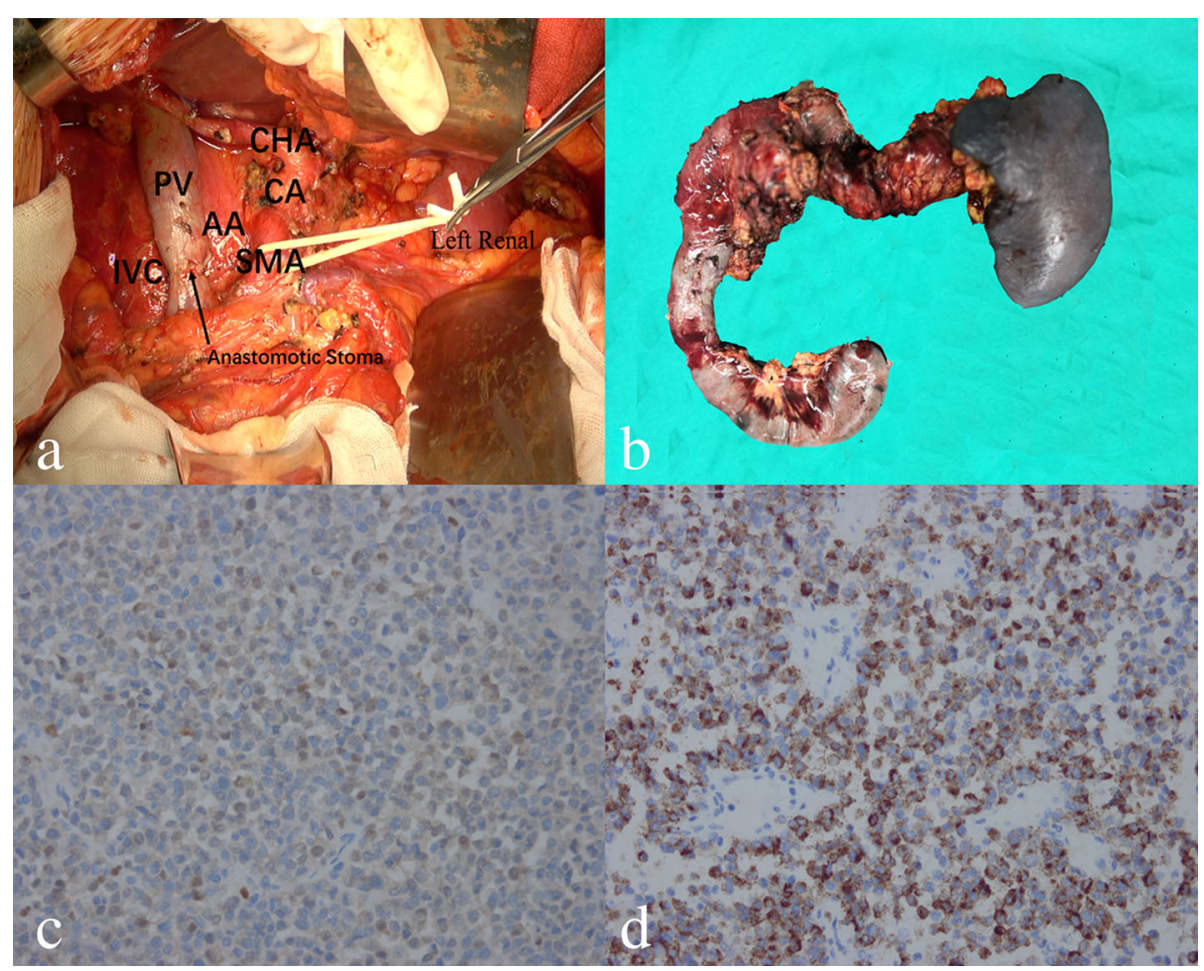

Fig. 2 Surgical field specimen after operation (a, b). Immunostaining of the tumor cells (S-100, C; Human Melanoma Black 45, D) 400x. IVC, inferior vena cava; CA, celiac artery; PV, portal vein; AA, abdominal aorta; CHA, common hepatic artery; SMA, superior mesenteric artery

pathological stage was stage IV [4]. The patient subsequently underwent high-dose interferon-alpha $2 \mathrm{~b}$ therapy. He was still alive 20 months after the operation without any evidence of recurrence.

\section{Discussion and conclusions}

MUP in pancreas is rather rare. In the literature review of Nakamura [5], a total of 76 pancreatic malignant melanoma cases were reported, published in English. The major primary site was cutaneous and ocular. In 10 cases, the primary site could not be located (Table 1). No standard guidelines have been developed to differentiate between primary and secondary pancreatic malignant melanoma. Primary malignant melanoma can rarely arise de novo from migrated neural crest cells, neural cells, or melanocytes [13]. The embryonic neural

Table 1 Overview of published cases of MUP in pancreas

\begin{tabular}{|c|c|c|c|c|c|c|c|c|c|}
\hline Authors & $\begin{array}{l}\text { Year of } \\
\text { publication }\end{array}$ & Age & Sex & $\begin{array}{l}\text { Location in the } \\
\text { pancreas }\end{array}$ & $\begin{array}{l}\text { Tumor size } \\
(\mathrm{cm})\end{array}$ & $\begin{array}{l}\text { Diagnostic } \\
\text { modality }\end{array}$ & Surgery & $\begin{array}{l}\text { Follow-up } \\
\text { (month) }\end{array}$ & Outcome \\
\hline Bianca et al .[6] & 1991 & 48 & M & Head & 3 & FNA & PD & 12 & Alive \\
\hline $\begin{array}{l}\text { Medina-Franco } \\
\text { et al. .[7] }\end{array}$ & 1999 & 60 & M & Head & 8 & $C T, \cup S$ & PD & 6 & Dead \\
\hline \multirow[t]{2}{*}{ Dewitt et al .[8] } & 2003 & 33 & M & Head & 5 & EUS-FNA & Palliative gastrojejunostomy & 6 & Dead \\
\hline & & 83 & $\mathrm{~F}$ & Tail & 3 & EUS-FNA & No operation & 10 & Alive \\
\hline Portale et al .[9] & 2011 & 43 & $\mathrm{~F}$ & Tail & 1.7 & US, CT, PET-CT & $\mathrm{DP}$ & NR & NR \\
\hline Sperti et al .[10] & 2011 & 48 & M & Body & 2.9 & $C T$ & DP & 24 & Dead \\
\hline \multirow[t]{2}{*}{ Goyal et al .[11] } & 2012 & 58 & $\mathrm{~F}$ & Head & 10 & CT-guided biopsy & PD & 11.4 & Dead \\
\hline & & 69 & M & Tail & 4.5 & Biopsy & DP & 26 & Dead \\
\hline $\begin{array}{l}\text { Ben Slama } \\
\text { et al .[12] }\end{array}$ & 2017 & 55 & $\mathrm{~F}$ & Head & 5.5 & $C T, M R I$ & PD & 15 & Alive \\
\hline Current & 2019 & 43 & M & Head, body, tail & - & US, CT, MRI, PET-CT & TP & 20 & Alive \\
\hline
\end{tabular}

$P D$ pancreatoduodenectomy, $D P$ distal pancreatectomy, TP total pancreatectomy, US ultrasonography, EUS-FNA endoscopic ultrasound-guided fine-needle aspiration biopsy, NR not report 
crest cells can give rise to islet cell tissue. The vagal neural crest cells play an important role in differentiation of endoderm-derived organs such as the thymus, lungs, and pancreas [14]. Melanocytic differentiation and melanin pigment formation were observed in some pancreatic tumors such as solid pseudopapillary neoplasms (SPN) [15]. Accordingly, some authors have postulated a neural crest origin of SPN [16]. Theoretically, neural crest cells and melanocytes can be seen in both normal and malignant pancreases, and malignant melanoma may occur primarily in the pancreas. Coincidentally, some investigators have probed whether gastrointestinal MUP may actually represent cases of primary melanoma derived from melanoblastic cells of the neural crest [17]. In our case, the recurrence-free survival time was 20 months. We therefore speculated that the patient in our case might have primary pancreatic malignant melanoma.

There are few reports of clinicians' experience with pancreatic malignant melanoma [5]. Most patients diagnosed with pancreatic malignant melanoma have undergone surgical resection. To our best knowledge, only two cases, including our own, have been treated with total pancreatectomy [18]. Curative resection of malignant pancreatic melanoma with portal and splenic vein thrombosis has not been reported in literature so far. Some researchers suggested that patients with pancreatic malignant melanoma may benefit from surgery when complete resection was possible [5, 11]. Wood et al. reported a series of 60 patients with metastatic melanoma of the gastrointestinal tract, and eight patients with metastatic lesions of the pancreas [19]. They found that six patients underwent complete surgical resection with a 5-year survival rate of 50\%. Regarding the effect of lymphadenectomy on survival, some study suggested that prompt radical lymph nodes dissection led to improved survival [20]. However, the prognostic advantage of radical lymph nodes dissection could not be conclusively determined in the systematic review [21]. But lymph nodes dissection is useful for staging [4]. Patients may also benefit from adjuvant therapies including immunotherapy, chemotherapy, or radiation therapy. MUP patients appear to have equivalent or better outcomes than patients with known primaries of a similar stage [2]. In our case, radical resection combined with chemotherapy was performed in a patient with macro-vascular invasion. At the time of writing this report, the patient has survived for more than 20 months.

In conclusion, primary malignant melanoma may theoretically occur in the pancreas. More studies on patients with pancreatic malignant melanoma, as well as a standardized definition of MUP and primary pancreatic malignant melanoma are needed in future. Wide local excision and lymph node dissection combined with chemotherapy may be an optimal treatment choice for locally advanced pancreatic malignant melanoma.

\section{Abbreviations \\ MUP: Melanoma of unknown primary; MRI: Magnetic resonance imaging; $C T$ : Computed tomography; SPN: Solid pseudopapillary neoplasms; IVC: Inferior vena cava; CA: Celiac artery; PV: Portal vein; AA: Abdominal aorta; CHA: Common hepatic artery; SMA: Superior mesenteric artery}

\section{Acknowledgements}

Not Applicable.

\section{Author contributions}

YJ contributed to manuscript writing and acquisition of the data. YJ and CR contributed to the critical revision of the manuscript for intellectual content. FL contributed to the critical revision of the manuscript for intellectual content. NC is the leader of the medical team. All authors read and approved the final manuscript.

\section{Funding}

This study is supported by Science and Technology Bureau of Sichuan Province (grant Nos 2019YFS0306, 2019YFS0041) in data collection and analysis.

Availability of data and materials

All data of this patient of this case report is included in this published article.

\section{Ethics approval and consent to participate}

The patient gave written informed consent. The ethics committee at West China Hospital has approved the case report to be submitted.

\section{Consent for publication}

Written informed consent for publication of their clinical details and clinical images was obtained from the patient.

\section{Competing interests}

No conflict of interest exits in the submission of this manuscript, and manuscript is approved by all authors for publication.

Received: 23 October 2019 Accepted: 27 March 2020

Published online: 16 April 2020

References

1. Chang AE, Karnell LH, Menck HR. The National Cancer Data Base report on cutaneous and noncutaneous melanoma: a summary of 84,836 cases from the past decade. The American College of Surgeons Commission on Cancer and the American Cancer Society. Cancer. 1998:83:1664-78.

2. Song Y, Karakousis GC. Melanoma of unknown primary. J Surg Oncol. 2019; 119:232-41.

3. Dasgupta T, Bowden L, Berg JW. Malignant melanoma of unknown primary origin. Surg Gynecol Obstet. 1963;117:341-5.

4. Gershenwald JE, Scolyer RA, Hess KR, Sondak VK, Long GV, Ross MI, et al. Melanoma staging: evidence-based changes in the American joint committee on Cancer eight edition cancer staging manual. CA Cancer J Clin. 2017;67:472-92

5. Nakamura Y, Yamada R, Kaneko M, Naota H, Fujimura Y, Tabata M, et al. Isolated pancreatic metastasis from malignant melanoma: a case report and literature review. Clin J Gastroenterol. 2019. https://doi.org/10.1007/s12328019-00996-6.

6. Bianca A, Carboni N, Di Carlo V, Falleni M, Ferrero S, Liverani C, et al. Pancreatic malignant melanoma with occult primary lesion. A case report. Pathologica. 1991;84:531-7.

7. Medina-Franco H, Halpern NB, Aldrete JS. Pancreaticoduodenectomy for metastatic tumors to the periampullary region. J Gastrointest Surg. 1999;3: 119-22.

8. Dewitt JM, Chappo J, Sherman S. Endoscopic ultrasound-guided fine-needle aspiration of melanoma metastatic to the pancreas: report of two cases and review. Endoscopy. 2003;35:219-22. 
9. Portale TR, Di Benedetto V, Mosca F, Trovato MA, Scuderi MG, Puleo S, et al. Isolated pancreatic metastasis from melanoma. Case report G Chir. 2011;32: 135-7.

10. Sperti C, Polizzi ML, Beltrame V, Moro M, Pedrazzoli S. Pancreatic resection for metastatic melanoma. Case report and review of the literature. J Gastrointest Cancer. 2011;42:302-6.

11. Goyal J, Lipson EJ, Rezaee N, Edil BH, Schulick R, Wolfgang CL, et al. Surgical resection of malignant melanoma metastatic to the pancreas: case series and review of literature. J Gastrointest Cancer. 2012;43:431-6.

12. Ben Slama S, Bacha D, Bayar R, Gharbi L, Lahmar A. Pancreatic resection for isolated metastasis from melanoma of unknown primary. Acta Gastroenterol Belg. 2017;80:323-4.

13. Bankar S, Patkar S, Desai S, Shrikhande SV. Unusual presentation of melanoma of unknown primary origin: a case report and review of literature. J Cancer Res Ther. 2015:11:1025.

14. Hutchins EJ, Kunttas E, Piacentino ML, Howard AGA 4th, Bronner ME, Uribe RA. Migration and diversification of the vagal neural crest. Dev Biol. 2018; 444:S98-S109.

15. Chen C, Jing W, Gulati P, Vargas H, French SW. Melanocytic differentiation in a solid pseudopapillary tumor of the pancreas. J Gastroenterol. 2004;39:579-83.

16. Cavard C, Audebourg A, Letourneur F, Audard V, Beuvon F, Cagnard N, et al. Gene expression profiling provides insights into the pathways involved in solid pseudopapillary neoplasm of the pancreas. J Pathol. 2009;218:201-9.

17. Manouras A, Genetzakis M, Lagoudianakis E, Markogiannakis H, Papadima A, Kafiri G, et al. Malignant gastrointestinal melanomas of unknown origin: should it be considered primary? World I Gastroenterol. 2007:13:4027-9.

18. Nikfarjam M, Evans P, Christophi C. Pancreatic resection for metastatic melanoma. HPB (Oxford). 2003;5:174-9.

19. Wood TF, DiFronzo LA, Rose DM, Haigh PI, Stern SL, Wanek L, et al. Does complete resection of melanoma metastatic to solid intra-abdominal organs improve survival? Ann Surg Oncol. 2001;8:658-62.

20. Chang P, Knapper WH. Metastatic melanoma of unknown primary. Cancer. 1982:49:1106-11.

21. Kamposioras K, Pentheroudakis G, Pectasides D, Pavlidis N. Malignant melanoma of unknown primary site. To make the long story short. A systematic review of the literature. Crit Rev Oncol Hematol. 2011;78:112-26.

\section{Publisher's Note}

Springer Nature remains neutral with regard to jurisdictional claims in published maps and institutional affiliations.

Ready to submit your research? Choose BMC and benefit from:

- fast, convenient online submission

- thorough peer review by experienced researchers in your field

- rapid publication on acceptance

- support for research data, including large and complex data types

- gold Open Access which fosters wider collaboration and increased citations

- maximum visibility for your research: over $100 \mathrm{M}$ website views per year

At $\mathrm{BMC}$, research is always in progress.

Learn more biomedcentral.com/submissions 